\title{
Etapas da terminologia como uma proposta de ensino e aprendizagem nas aulas de inglês instrumental
}

\author{
Terminology steps as a proposal for teaching and learning English in ESP \\ classroom
}

Gyzely Suely Lima*

\begin{abstract}
RESUMO: O objetivo deste artigo é apresentar uma reflexão sobre a experiência de desenvolvimento das etapas iniciais da Terminologia como uma metodologia da Linguística de Corpus no ensino e na aprendizagem de língua inglesa na perspectiva do Datadriven Learning (DDL). Apresentamos as perspectivas teórica e prática no uso do DDL (JOHNS, 1991) para o ensino e aprendizagem de inglês, partindo dos princípios da Teoria Comunicativa da Terminologia (TCT) (ALMEIDA, 2006) e da Linguística de Corpus (BERBERSARDINHA, 2004; SCOTT, 2012; TEIXEIRA, 2008) como uma abordagem teórica. A descrição de uso prático do DDL nas aulas de inglês inicia-se com a experiência vivida com um grupo de estudantes de um curso superior de Tecnologia em Logística, sugerindo desdobramentos para a continuidade da proposta como uma forma de criar a oportunidade nas aulas de Inglês Instrumental para os alunos aprenderem inglês por meio de um corpus de textos autênticos.
\end{abstract}

PALAVRAS-CHAVE: Data-driven Learning. Teoria Comunicativa da Terminologia. Linguística de Corpus. Inglês Instrumental.

\begin{abstract}
The aim of this study is to present a reflection about a possibility of using Corpus Linguistics methodology for teaching and learning English based on Data-driven Learning (DDL) perspective in an English for Specific Purpose (ESP) classroom. Both theoretical and practical perspectives of the use of Datadriven Learning (DDL) (JOHNS, 1991) are presented here related to teaching and learning English, by considering the principals of Communicative Terminology Theory (ALMEIDA, 2006) and Corpus Linguistics as an approach (BERBER-SARDINHA，2004; SCOTT, 2012; TEIXEIRA, 2008). The description of practical use of DDL in English classrooms starts from the living experience shared with a group of students enrolled in an undergraduate course of Technology in Logistics. Furthermore this study suggests potential ways to continue the proposal in order to give the opportunity to students for learning English from a corpus of authentic texts in English for Specific Purpose (ESP) classes.
\end{abstract}

KEYWORDS: Data-driven Learning. Terminology Communicative Theory. Corpus Linguistics. English for Specific Purpose.

\footnotetext{
* Doutora em Estudos Linguísticos. Docente Instituto Federal do Triângulo Mineiro - IFTM.
} 


\section{Introdução}

Há alguns anos, o uso das tecnologias digitais nas aulas de inglês tem se tornado cada vez mais acessível nas instituições públicas de ensino, o que tem desencadeado uma série de pesquisas na área da Linguística Aplicada sobre diversos temas. $\mathrm{O}$ objetivo deste artigo é apresentar uma reflexão sobre a possibilidade de uso da metodologia da Linguística de Corpus no ensino e na aprendizagem de língua inglesa na perspectiva do Data-driven Learning (DDL). Apresentamos as perspectivas teórica e prática no uso do DDL (JOHNS, 1991) para o ensino e a aprendizagem de inglês, partindo dos princípios da Teoria Comunicativa da Terminologia (doravante TCT) (ALMEIDA, 2006) e da Linguística de Corpus (BERBER-SARDINHA, 2004; SCOTT, 2012; TEIXEIRA, 2008) como uma abordagem teórica. A descrição de uso prático do DDL nas aulas de inglês inicia-se com a experiência vivida com um grupo de estudantes de um curso superior de Tecnologia em Logística, sugerindo desdobramentos para a continuidade da proposta como uma forma de criar a oportunidade nas aulas de Inglês Instrumental para os alunos aprenderem inglês por meio de um corpus de textos autênticos.

A estrutura deste artigo consiste em, primeiramente, apresentar a fundamentação teórica na qual embasamos este estudo. Na sequência, descrevemos a metodologia da Linguística de Corpus utilizada no desenvolvimento da pesquisa, ressaltando as etapas da Terminologia. Nas considerações finais, discutimos algumas limitações do estudo e apontamos os desdobramentos futuros, propostas para continuidade do desenvolvimento do vocabulário técnico da área de Logística partindo dos resultados alcançados. 


\section{Pressupostos teóricos}

Nesta seção apresentamos a fundamentação teórica deste estudo expondo a concepção de DDL que consideramos para esta pesquisa, apresentamos os princípios da Teoria Comunicativa da Terminologia (TCT), expondo a perspectiva da Linguística de Corpus (LC) como a abordagem de estudo.

O entendimento da Linguística de Corpus (LC) como uma área da Linguística, cujo trabalho consiste na compilação e análise de corpora, está presente nos trabalhos de estudiosos brasileiros (BERBER SARDINHA, 2004; VIANA; TAGNIN, 2011) e internacionais (BIBER; CONRAD; REPPEN, 1998; TOGNINI-BONELLI, 2001). De acordo com esses teóricos define-se corpora como as grandes coleções de textos eletrônicos (orais e/ou escritos, sincrônicos ou diacrônicos, dentre outras classificações) que podem ser específicos ou abrangentes. É válido destacar que conforme a quantidade de idiomas em que o corpora se encontra, é possível realizar análises paralelas e contrastivas. Além de haver corpora existentes e disponíveis para os pesquisadores, como o Corpus of Contemporary American English - COCA ${ }^{1}$ (DAVIES, 2014), há a possibilidade de se compilar o seu próprio corpus que auxiliados por programas de análise lexical, como o Wordsmith Tools (SCOTT, 2008) e o Antconc (ANTHONY, 2014), que efetuam operações de processamento da linguagem, destacando a geração de listas de palavras-chave e exibição de linhas de concordância. Berber-Sardinha (2004, p. 272) destaca uma das características desse tipo de operação da linguagem ao explicar que uma linha de concordância "mostra a palavra de busca no centro da listagem ladeada pelas palavras que ocorreram no texto junto com ela". No nosso estudo, percebemos que quando o aluno se utiliza desse tipo de operação da linguagem ele pode ampliar sua visão de entendimento do vocabulário específico da área em questão ao relacioná-lo com seu contexto. Assim, o seu aprendizado de língua

\footnotetext{
${ }^{1}$ http://corpus.byu.edu/coca/
} 
pode ser direcionado pelos dados que os corpora lhe oferecem. Por conta dessa possibilidade, buscamos entender os pressupostos do DDL como uma metodologia na sala de aula de língua inglesa.

Segundo Ma (1993), o DDL, também denominado Computerized Concordancing (CC), é uma forma de análise de texto e tem sido usada nas áreas da Linguística Computacional e Linguística de Corpus. $\mathrm{O}$ autor afirma que a análise computadorizada de texto está mais próxima de professores e alunos a partir da década de 80, com os trabalhos de Higgins e Johns (1984) e Johns (1986, 1988), por causa do acesso a computadores em sala de aula na perspectiva da aprendizagem mediada pelo computador (computer-assisted language learning - CALL). Ma (1993) esclarece, dessa forma, que se tornou mais acessível a possibilidade de uso de concordância de um corpus pequeno como uma atividade didática que tem sido cada vez mais experimentada em escolas onde se tem computadores disponíveis.

Johns (1986) define que a abordagem do DDL se caracteriza pelos dados de linguagem serem considerados como papel primordial na aprendizagem de língua. Ma (1993) explica dois modos de aplicação do DDL: pré-sala de aula ou o uso em sala de aula. O uso prévio do DDL consiste na transformação dos resultados do DDL em material didático, por exemplo, na elaboração de tarefas e exercícios. Por outro lado, o uso em sala de aula representa o uso interativo das linhas de concordância. Nessa perspectiva, o professor direciona os alunos a gerar as linhas de concordâncias para um estudo de uso da língua. Nesse mesmo sentido, Levy (1990) sugere que a integração de concordância on-line com o software de escrita (word-processor) permite criar um ambiente plenamente integrado de processamento de palavras. No aspecto prático deste estudo, identificamos que, nas aulas de Inglês Instrumental, houve esse segundo tipo de aplicação do DDL, de modo que a professora sugeriu aos alunos que fizessem a compilação do corpus da área de Logística e posteriormente, usando o software Antconc, os alunos identificassem as concordâncias presentes nas palavras- 
chave da lista de palavras. O objetivo dessa atividade foi criar um glossário de termos técnicos específicos da área em questão durante as aulas de língua inglesa. Baseandose nessa meta, é relevante considerarmos os princípios da TCT que fornece subsídios para entendermos como ocorre esse processo de criação de dicionários, vocabulários e glossários com essa finalidade.

Almeida (2006) explica que a TCT surge como novos paradigmas, a partir da década de 90, por causa da insuficiência teórica e metodológica da Teoria Geral da Terminologia (TGT) para a criação de produtos terminológicos. A autora esclarece que a TCT se tornou uma referência teórica para a maioria das pesquisas terminológicas no Brasil, fundamentando-se nos pilares teóricos e metodológicos concebidos principalmente por Cabré (1999). Segundo Almeida (2006), dentre os pressupostos gerais da TCT destacam-se as unidades terminológicas, que são o objeto central da Terminologia, reforçando uma perspectiva linguística e uma abordagem semasiológica; e a equivalência a priori entre termo e palavra, considerando que os signos linguísticos que podem realizar-se no discurso como termo ou palavra, dependendo da situação comunicativa.

Tendo em vista que: i) a diferença entre termo e palavra se observa, fundamentalmente, na situação comunicativa; ii) os termos devem ser observados no seu ambiente natural de ocorrência, e iii) a variação conceitual e denominativa deve ser considerada; é extremamente importante a variação de gêneros textuais para compor o corpus (ALMEIDA, 2006, p. 88).

Tais pressupostos teóricos da TCT, neste estudo, nos propiciou pensar sobre a relevância de esclarecer para tais possibilidades de interpretação de um termo ou uma palavra para os alunos que estão aprendendo inglês como língua estrangeira. Entendemos que o uso da metodologia DDL nas aulas de Inglês Instrumental permite identificar a necessidade de observar os termos no seu ambiente natural de ocorrência, nos discursos especializados da área da Logística, por exemplo. Assim, o aluno pode 
se tornar mais ativo e atento no seu processo de aprendizagem de inglês, ao aprender um novo vocabulário, considerando a variação conceitual e denominativa de um termo ou uma palavra.

Por meio dos pressupostos teóricos da Teoria Comunicativa da Terminologia (TCT), Almeida (2006) argumenta sobre a relevância das seguintes etapas na organização de um dicionário de uma área específica: a organização do corpus, a elaboração do mapa conceitual, o planejamento do protocolo de preenchimento das fichas terminológicas, a redação das definições, a organização do verbete e a configuração da macroestrutura.

\section{Metodologia}

A metodologia para este estudo envolveu as seguintes fases: a escolha da área, a criação de uma árvore de domínio da área da Logística, a compilação de um corpus de estudo feita por alunos durante as aulas de Inglês Instrumental, a escolha e o uso do programa de análise-lexical e a definição da macroestrutura (a listagem de palavras, as palavras-chave e as linhas de concordância).

\section{ESCOLHENDO A ÁREA}

Como um estudo de linguística aplicada e uma proposta de trabalho terminográfico, levamos em consideração a necessidade de acesso às informações sobre a área da Logística e a possibilidade de contato com os profissionais especialistas que atuam nesse campo. Dessa forma, para a elaboração da árvore de domínio, pesquisamos fontes, como a matriz curricular de cursos superiores de Logística e a tabela de áreas de conhecimento da Capes, para identificarmos onde a subárea da Logística se encaixa; buscamos o contato com os pesquisadores especialistas da área, que neste estudo foram os docentes de um curso superior em Logística, para auxiliarnos na elaboração da árvore de domínio e, posteriormente, na validação dos verbetes. 
Primeiramente, a escolha da área da Logística deu-se por causa da oportunidade que surgiu de utilizarmos computadores durante as aulas de Inglês Instrumental, em que eu atuo como professora, no curso superior de Tecnologia em Logística na instituição de ensino e a possibilidade de repensar a metodologia de ensino e aprendizagem de inglês por meio do DDL. Dessa forma, consideramos relevante descrever o contexto no qual a pesquisa de campo aconteceu durante o segundo semestre de 2014.

O contexto de coleta de dados para esta pesquisa foi um dos campi que integra uma instituição pública de ensino que oferece cursos profissionalizantes em níveis de ensino médio, graduação e pós-graduação. Sou professora nessa instituição desde 2010. Pelo próprio site da instituição, no link histórico, descobrimos que essa instituição tem passado por adaptações desde 2009, visando implementar uma nova perspectiva de ensino. As escolas agrotécnicas e os centros de formação técnica foram abarcados como uma proposta do governo federal e se tornaram Institutos Federais. Assim sendo, o ensino tecnológico comumente desenvolvido nesses contextos teve de se ajustar para a proposta da verticalização de ensino, a qual propõe que o estudante passaria então por um processo de formação com objetivos que vão além da simples capacitação de mão de obra para o mercado de trabalho, oferecendo ao estudante a possibilidade de continuar os estudos e a vida acadêmica na mesma instituição por meio de cursos de graduação e pós-graduação.

A pesquisa de campo deste estudo foi desenvolvida no campus dessa instituição em que eu trabalhava na época. Penso ser relevante relacionar alguns detalhes tanto da estrutura física do campus da unidade, que foi o contexto desta pesquisa, quanto da estrutura pedagógica do curso, em que vivemos a experiência de ensinar e aprender inglês por meio das tecnologias digitais nas aulas do curso de Inglês Instrumental. 
O espaço físico em que aulas de Inglês Instrumental aconteceram consistiu em dois ambientes: uma sala de aula e um laboratório de computadores (conforme figuras 1 e 2). O laboratório de computadores, onde aconteceram as aulas desta pesquisa, fica no piso térreo da instituição e cada aluno tinha um computador disponível para usar. Todas as máquinas estavam conectadas à internet e poderiam ser acessadas pelos alunos que usavam seu usuário e senhas cadastrados no início do semestre.

Figura 1 - Foto do laboratório de informática.

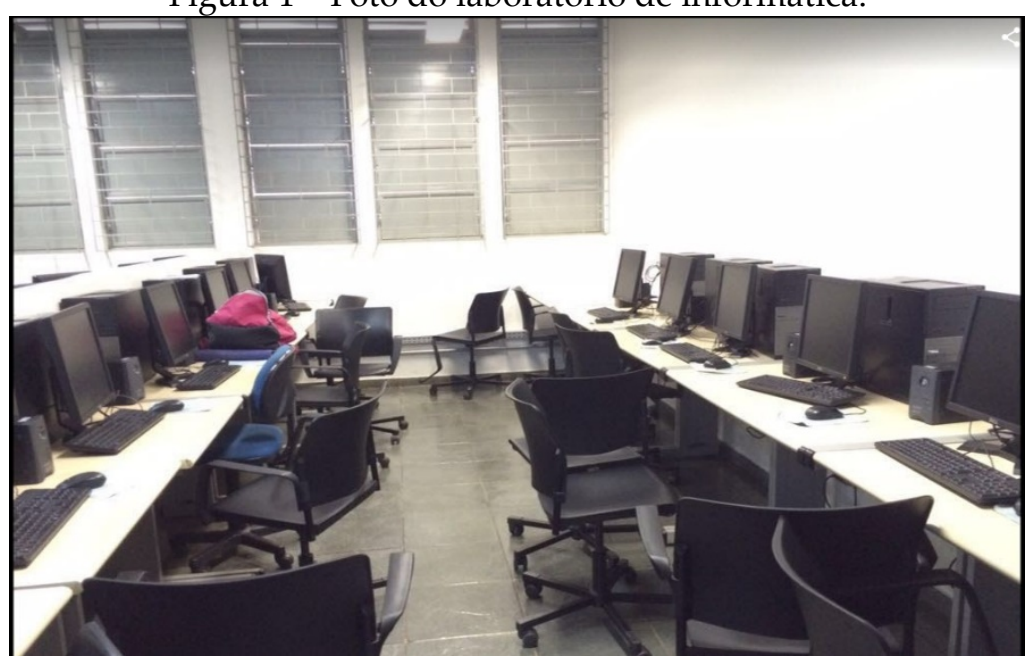

Fonte: Fotografia do acervo da autora, novembro de 2015.

Figura 2 - Foto da sala de aula.

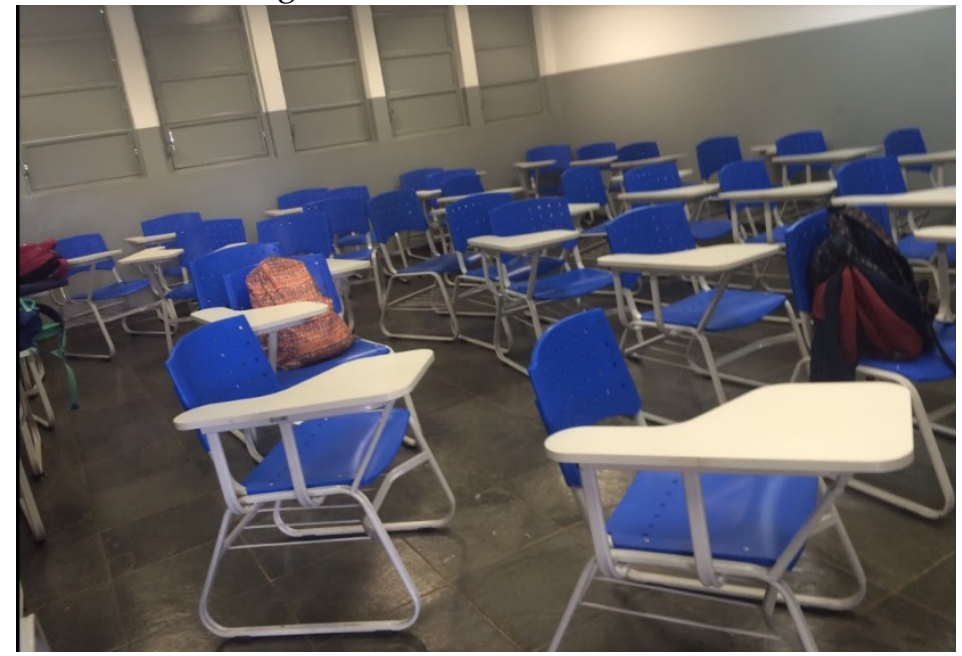

Fonte: Fotografia do acervo autora, novembro de 2015. 
Essa descrição detalhada sobre a instituição e a infraestrutura nos contextos desta pesquisa auxilia a compreender como as circunstâncias propiciaram o uso do computador durante as aulas de inglês e a entender a matriz curricular do curso de Logística. Essa matriz foi fonte para elaborarmos a nossa proposta de árvore de domínio.

Ao longo da pesquisa percebemos que este estudo pode, também, contribuir tanto para a área da Linguística Aplicada quanto para a da Logística, que como subárea não se encontra relacionada na atual Tabela de Áreas de Conhecimento organizada pela Capes, conforme discutiremos na seção a seguir.

\section{ELABORANDO A ÁRVORE DE DOMÍNIO}

Segundo Krieger e Finatto (2004), é importante a construção de árvores de domínio para estabelecimento das relações semânticas e conceituais de determinada área. Dessa forma, neste estudo, a elaboração da árvore de domínio pode permitir perceber e representar um modo de organização conceitual e semântico da área da Logística como esta está inserida nos seus habitats textuais. É válido destacar que Dornelles (2015, p. 171) chama a atenção para o fato de que a árvore de domínio é apenas uma das formas de representação utilizadas na Linguística de Corpus e que é uma interpretação de inter-relações de termos-chave dentro de um sistema conceitual proposto, pois comumente entre os especialistas da área em questão não há consenso sobre suas (sub)divisões, seus conceitos e suas denominações.

Para o desenvolvimento dessa etapa da pesquisa, Fromm (2014) nos orienta a pesquisar por árvores de domínio já existentes, ou elaborar uma própria por meio da montagem de um esboço baseado em matrizes curriculares ou textos na própria área para termos uma noção de como ela se subdivide e, posteriormente, consultar os especialistas para que possam validar o trabalho. 
Neste estudo começamos a pesquisa pelo site da Capes, no qual encontramos árvores com as grandes áreas do conhecimento. Sobre essa fonte, Fromm (2014) ressalta o fato de que o desenvolvimento dessas árvores é incompleto e isto se torna um problema para os pesquisadores.

É relevante explicar que, segundo a Capes, a classificação das Áreas do Conhecimento tem finalidade eminentemente prática, cujo objetivo é proporcionar às instituições de ensino, pesquisa e inovação uma maneira ágil e funcional de sistematizar e prestar informações concernentes a projetos de pesquisa e recursos humanos aos órgãos gestores da área de ciência e tecnologia.

Sobre a organização das Áreas do Conhecimento na tabela, de acordo com a Capes, há uma hierarquização em quatro níveis, do mais geral ao mais específico, abrangendo nove grandes áreas nas quais se distribuem as 48 áreas de avaliação da Capes. Essas áreas de avaliação, por sua vez, agrupam áreas básicas (ou áreas do conhecimento), subdivididas em subáreas e especialidades.

A seguir, apresentamos uma árvore de domínio em que identificamos a subárea da Logística em um projeto de 2005 (o qual não se consolidou), da Capes e, na sequência, a mesma área de conhecimento na versão de 2016 da Tabela de Áreas de Conhecimento que está disponível no site da Capes. 
Figura 3 - Árvore Capes/CNPq - Proposta Capes/CNPq 2005.
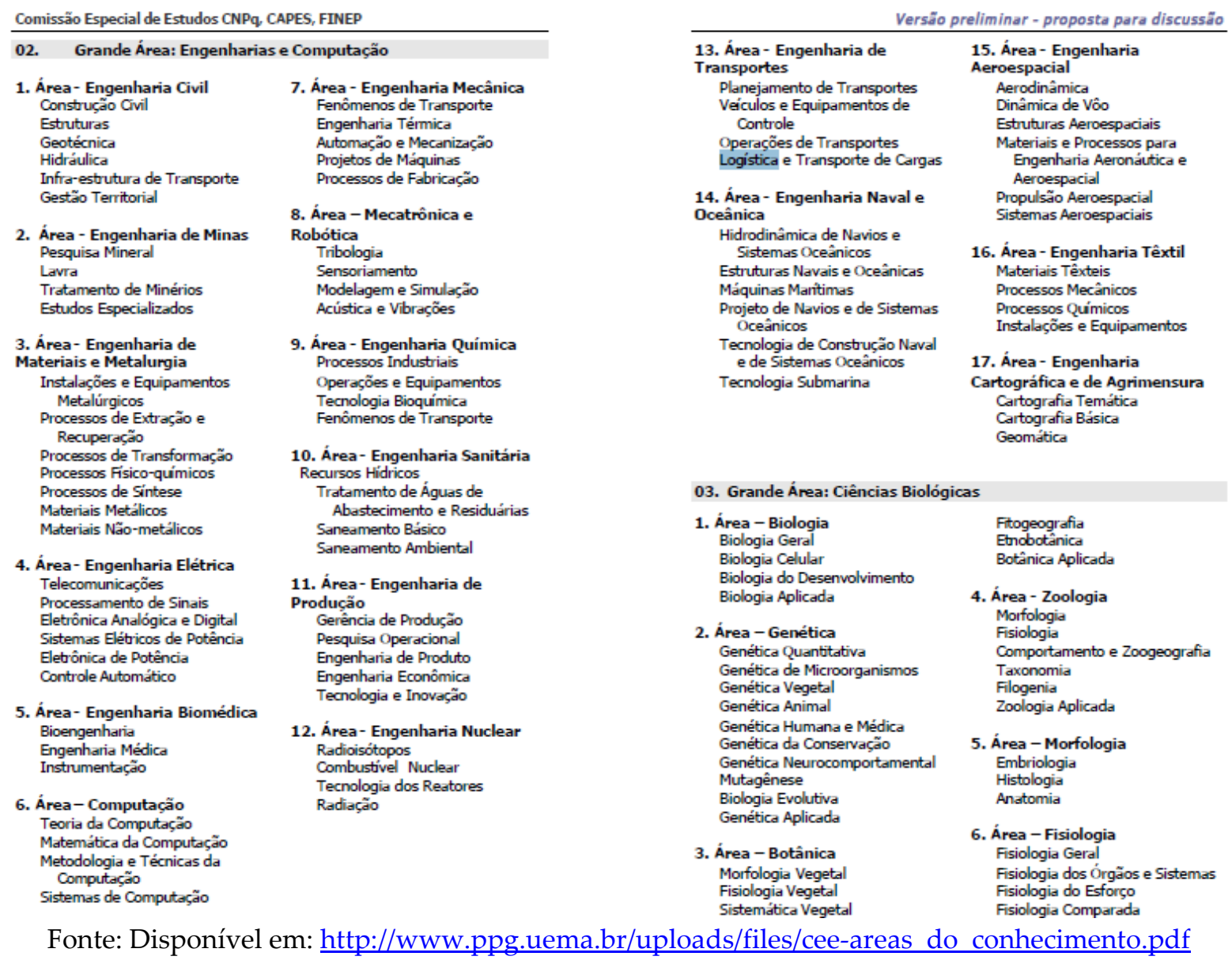

Fonte: Disponível em: http://www.ppg.uema.br/uploads/files/cee-areas do conhecimento.pdf

Nessa versão do projeto de 2005 da Capes, a subárea da Logística está relacionada à grande área de Engenharia e Computação. De acordo com os critérios estabelecidos pela Capes, a grande área refere-se à aglomeração de diversas áreas do conhecimento, em virtude da afinidade de seus objetos, métodos cognitivos e recursos instrumentais refletindo contextos sociopolíticos específicos. Dentro dessa área, considerada $1^{\circ}$ nível, a Logística foi categorizada como $3^{\circ}$ nível, estando listada dentro da área de conhecimento (área básica) de Engenharias de Transportes. Dessa forma, a Logística como subárea é reconhecida nessa hierarquização como uma segmentação da área do conhecimento (ou área básica) estabelecida em função do objeto de estudo e de procedimentos metodológicos reconhecidos e amplamente utilizados. 
Vamos observar agora como está essa mesma área de conhecimento, Engenharia de Transportes, na versão de 2016 da Tabela de Áreas de Conhecimento disponível no site da Capes, conforme Figura 4.

Figura 4 - Árvore Capes/CNPq - Tabela Atual (2016) Capes/CNPq.

31000002

31001009

31001017

31001025

31002005

31002013

31002021

31002030

31002048

31003001

31003010

31003028

31003036

\section{ENGENHARIA DE TRANSPORTES}

PLANEJAMENTO DE TRANSPORTES

PLANEJAMENTO E ORGANIZAÇÃO DO SISTEMA DE TRANSPORTE

ECONOMIA DOS TRANSPORTES

VEÍCULOS E EQUIPAMENTOS DE CONTROLE

VIAS DE TRANSPORTE

VEÍCULOS DE TRANSPORTES

ESTAÇÃO DE TRANSPORTE

EQUIPAMENTOS AUXILIARES E CONTROLES

OPERAÇÕES DE TRANSPORTES

ENGENHARIA DE TRÁFEGO

CAPACIDADE DE VIAS DE TRANSPORTE

OPERAÇÃO DE SISTEMAS DE TRANSPORTE

ÁREA DE AVALIAÇÄO: ADMINISTRAÇÃO, CIÊNCIAS CONTÁBEIS E TURISMO

\begin{tabular}{ll}
60200006 & \multicolumn{1}{c}{ ADMINISTRAÇÃO } \\
60201002 & ADMINISTRAÇÃO DE EMPRESAS \\
60201010 & ADMINISTRAÇÃO DE PRODUÇÃO \\
60201029 & ADMINISTRAÇÃO FINANCEIRA \\
60201037 & MERCADOLOGIA \\
60201045 & NEGÓCIOS INTERNACIONAIS \\
60201053 & ADMINISTRAÇÃO DE RECURSOS HUMANOS \\
60202009 & ADMINISTRAÇÃO PÚBLICA \\
60202017 & CONTABILIDADE E FINANÇAS PÚBLICAS \\
60202025 & ORGANIZAÇÕES PÚBLICAS \\
60202033 & POLITICA E PLANEJAMENTO GOVERNAMENTAIS \\
60202041 & ADMINISTRAÇÃO DE PESSOAL \\
60203005 & ADMINISTRAÇÃO DE SETORES ESPECIFICOS \\
60204001 & CIÊNCIAS CONTÁBEIS
\end{tabular}

Fonte: Disponível em http://www.CAPES.gov.br/avaliacao/instrumentos-de-apoio/tabela-de-areas-doconhecimento-avaliacao.

Na Figura 4, relacionamos a área de conhecimento de Administração na tentativa de localizar a subárea da Logística por sugestão de pesquisa dos especialistas da área que foram entrevistados nesta pesquisa. Nessa versão de 2016, não aparece a subárea da Logística nem na área de Engenharias de Transportes e tampouco na de 
Administração. Questionamos o que aconteceu da versão do projeto de 2005 até essa versão atual de 2016: por que a subárea da Logística deixou de ser considerada uma segmentação de área de conhecimento? Como as instituições de ensino que oferecem especificamente o curso superior de Logística têm sistematizado e prestado informações concernentes a projetos de pesquisa e recursos humanos relacionados a essa área aos órgãos gestores da área de ciência e tecnologia?

Corroborando a problematização apontada por este estudo, há uma pesquisa ainda em progresso, coordenada por Fromm ${ }^{2}$, em que foram analisadas as grades curriculares do curso de Logística oferecido por três instituições de ensino (Universidade Federal de Uberlândia, Senac e Fundação Getúlio Vargas). Dessa análise, Fromm propõe a seguinte árvore de domínio:

\footnotetext{
${ }^{2}$ Professor Guilherme Fromm é doutor em Letras (Estudos Linguísticos e Literários em Inglês - 2008), pela Universidade de São Paulo. Atualmente é professor Adjunto do Ileel/UFU, área de Língua Inglesa, e tem experiência na área de Linguística, atuando principalmente nos seguintes temas: Linguística de Corpus, Lexicologia, Terminologia, Terminografia bilíngue e Tradução. Fonte: Disponível em http://lattes.cnpq.br/6627254642763875.
} 
Figura 5 - Árvore de domínio da Logística proposta por Fromm

Made with Text2MindMap.com

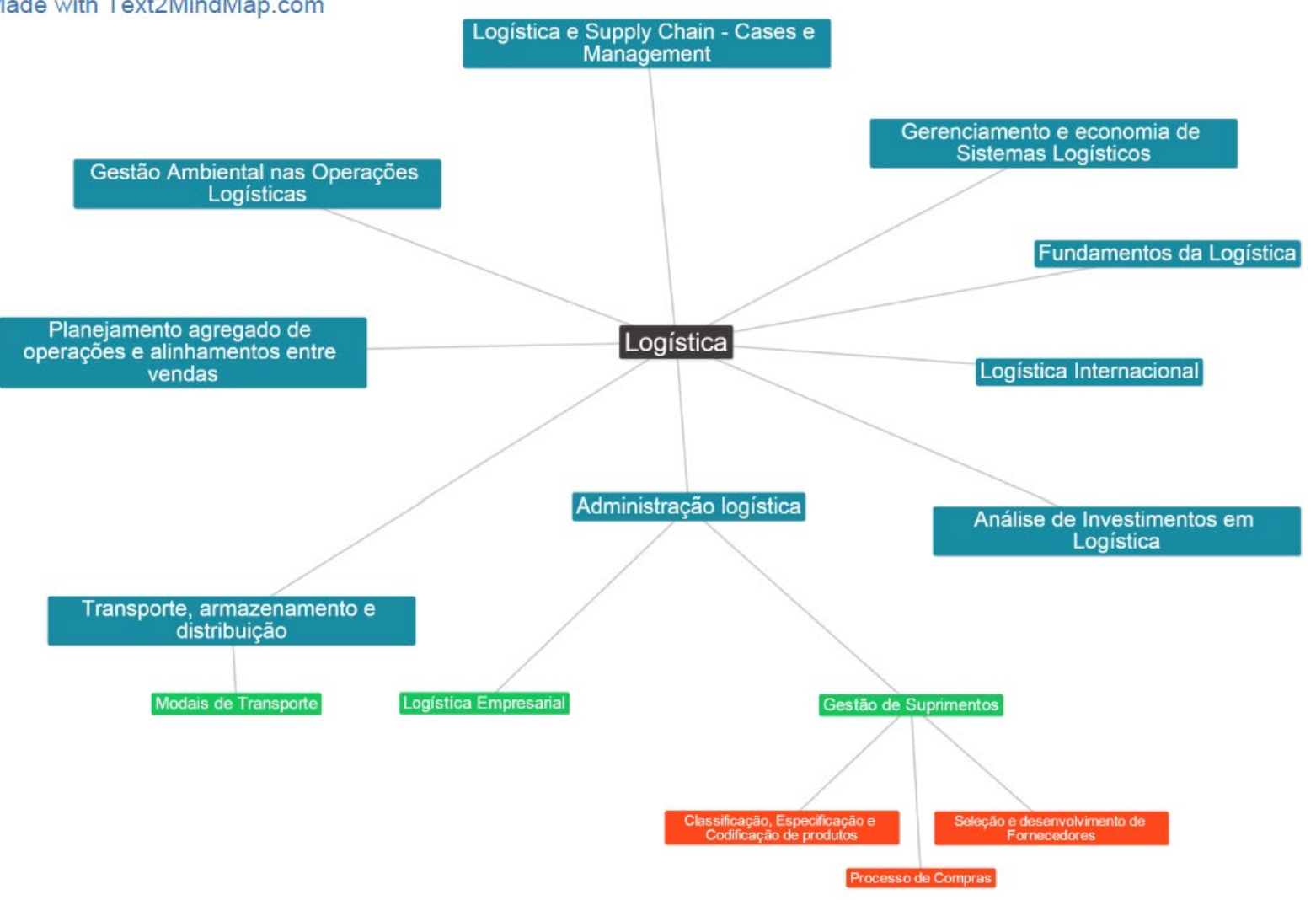

Fonte: Figura fornecida pelo autor.

Essa árvore de domínio da Logística pode ser um referente para analisarmos a nossa própria árvore de domínio apresentada neste estudo. Seguindo as orientações propostas por Fromm (2014), descrevemos a seguir como elaboramos a nossa proposta de árvore de domínio.

Para a criação da nossa árvore de domínio partimos da análise da matriz curricular do curso superior de Tecnologia em Logística da instituição de ensino em que aconteceu a pesquisa de campo durante as aulas de Inglês Instrumental, conforme a seguinte sequência de disciplinas. 
Quadro 1 - Matriz curricular do curso superior de Tecnologia em Logística.

\begin{tabular}{|c|c|c|c|}
\hline & \multicolumn{3}{|c|}{ Núcleos de Formação } \\
\hline & Básica & Específica & Complementar \\
\hline 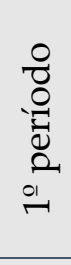 & $\begin{array}{l}\text { *Introdução à } \\
\text { Administração e à Logística } \\
\text { *Gestão de Marketing e } \\
\text { Serviço ao Cliente }\end{array}$ & $\begin{array}{l}\text { *Introdução aos Modais de } \\
\text { Transporte } \\
\text { *Gestão da Produção }\end{array}$ & $\begin{array}{l}\text { * Matemática Aplicada } \\
\text { à Gestão } \\
\text { *Métodos e Técnicas de } \\
\text { pesquisa }\end{array}$ \\
\hline 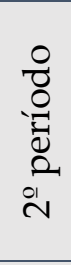 & $\begin{array}{l}\text { * Estratégia Empresarial } \\
\text { * Gestão Financeira I } \\
\text { * Estatística }\end{array}$ & * Gestão de Qualidade & $\begin{array}{l}\text { * Informática Aplicada } \\
\text { à Gestão } \\
\text { * Comunicação } \\
\text { Empresarial }\end{array}$ \\
\hline 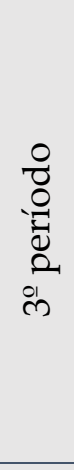 & $\begin{array}{l}\text { * Economia } \\
{ }^{*} \text { Gestão Financeira II }\end{array}$ & $\begin{array}{l}\text { *Gestão de Estoque, } \\
\text { Armazenamento e } \\
\text { Movimentação } \\
\text { * Gestão de Frotas e } \\
\text { Roteirização } \\
\text { *Gestão e Processos de } \\
\text { Compras }\end{array}$ & $\begin{array}{l}\text { * Inglês Instrumental } \\
\text { * Projeto } \\
\text { Multidisciplinar }\end{array}$ \\
\hline 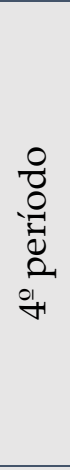 & $\begin{array}{l}\text { *Gestão de Varejo } \\
{ }^{*} \text { Gestão de Pessoas }\end{array}$ & $\begin{array}{l}\text { * Estratégia de Loc. e Arranjo } \\
\text { Físico } \\
\text { * Logística Internacional } \\
\text { * Prestadores de Serviços } \\
\text { Logísticos } \\
\text { * Pesquisa Operacional I }\end{array}$ & $\begin{array}{l}{ }^{*} \text { Projeto } \\
\text { Multidisciplinar }\end{array}$ \\
\hline 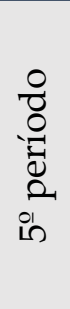 & $\begin{array}{l}\text { *Gestão de Projetos } \\
\text { * Empreendedorismo }\end{array}$ & $\begin{array}{l}\text { * Logística e Comércio } \\
\text { Eletrônico } \\
\text { * Tópicos Especiais } \\
\text { *Pesquisa Operacional II }\end{array}$ & $\begin{array}{l}\text { * Gestão Tributária } \\
\text { * Libras (optativo) }\end{array}$ \\
\hline
\end{tabular}

Fonte: Matriz Curricular do curso superior de Tecnologia em Logística, disponível no site da instituição pesquisada.

Buscamos validar nossa proposta de árvore de domínio por meio de entrevistas com profissionais especialistas da área de Logística; foram consultados dois 
professores da área de Logística que trabalham nessa mesma instituição da matriz curricular (Quadro 1). Segundo os especialistas, a Logística faz parte de uma das subáreas da Gestão, também denominada Administração. As disciplinas presentes na matriz curriculares seriam divididas da seguinte forma, considerando com as cinco subáreas da Gestão: Logística, Produção, Marketing, Gestão Financeira e Gestão de Pessoas. A seguir apresentamos a árvore de conhecimento elaborada durante este estudo:

Figura 6 - Árvore de domínio da Logística.

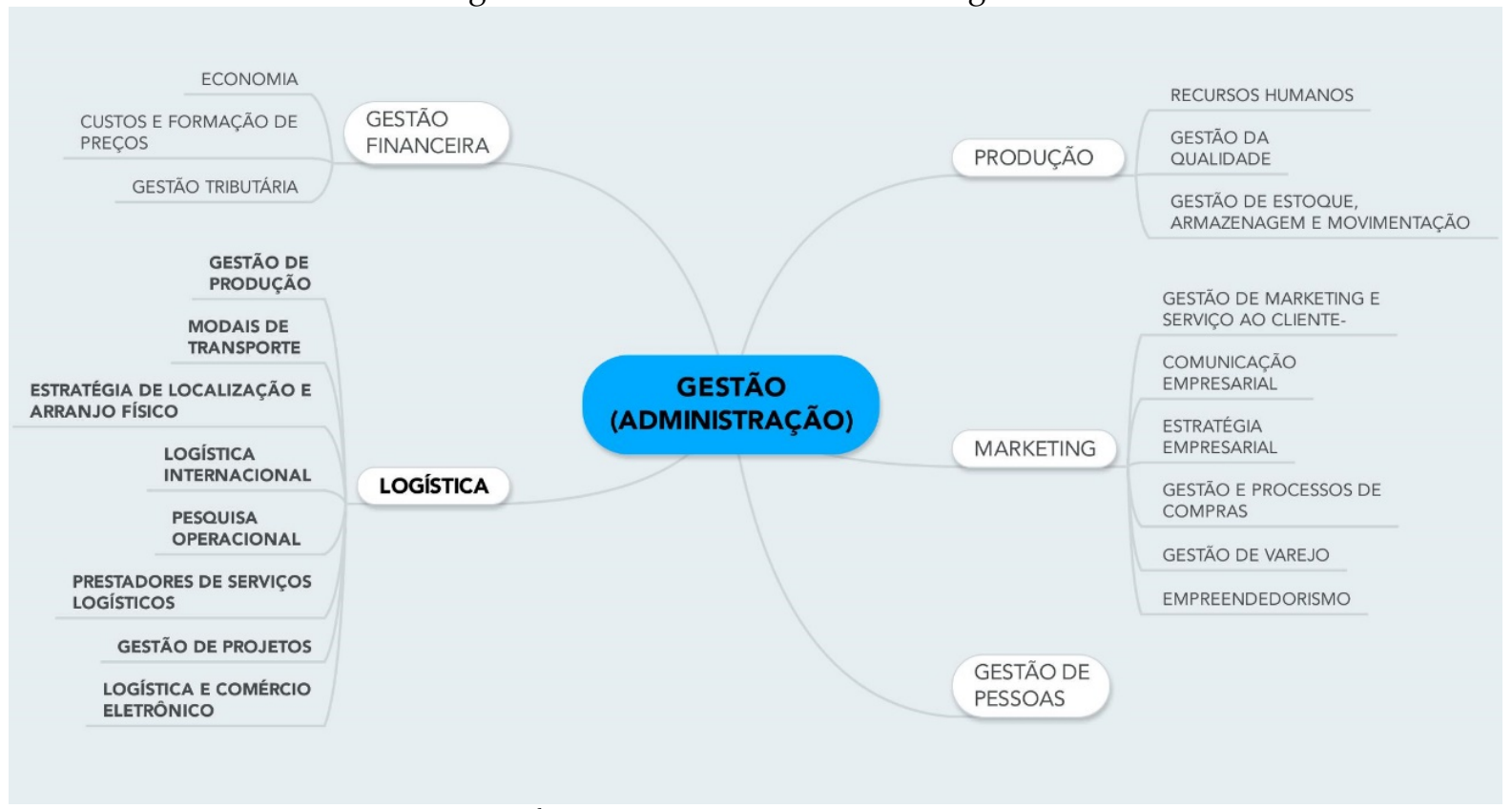

Fonte: Árvore de domínio criada pela autora.

Durante a entrevista, os especialistas da área comentaram sobre a abrangência de algumas subáreas que poderiam estar categorizadas tanto na Logística quanto nas outras subáreas, por exemplo, Gestão de Projetos. Conforme relacionado na árvore do conhecimento acima, vemos que a Logística está dentro da área de conhecimento da Administração no mesmo nível de outras quatro subáreas: Gestão de Pessoas, Marketing, Produção e Gestão Financeira. Sob a subárea da Logística, encontram-se oito subáreas: Gestão de produção; Modais de transporte; Estratégia de localização e 
arranjo físico; Logística internacional; Pesquisa operacional; Prestadores de serviços logísticos; Gestão de projetos; e Logística e Comércio eletrônico.

Acreditamos que este estudo possa contribuir para acrescentar conhecimento à literatura da área e, de alguma forma, auxiliar os especialistas diante da problematização da questão da tabela de conhecimentos da Capes.

Depois de elaborada a nossa própria árvore do domínio, partimos dessa proposta para iniciarmos a compilação do corpus de análise com os alunos durante as aulas de Inglês Instrumental. O objetivo geral dos alunos nas aulas de Inglês Instrumental era desenvolver as estratégias de leitura de textos em língua inglesa, referentes à área de Logística, aprimorando o vocabulário técnico. Os alunos haviam compartilhado na primeira aula as dificuldades que tinham em encontrar glossários bilíngues (português- inglês) específicos de Logística. A meu ver, como professora, aos alunos lhes faltava mais conhecimentos de como eles próprios poderiam entender e construir as definições de termos em inglês de Logística por meio do estudo de textos específicos da área. Penso que envolver os alunos na construção de um glossário bilíngue específico da área de Logística possa atender à sua necessidade de entender os termos técnicos em inglês, desenvolvendo as estratégias de leitura nessa língua estrangeira, além de contribuir para estudos da Linguística de Corpus. Segundo Fadanelli e Finatto (2015), os alunos podem apresentar dúvidas em uma porcentagem relevante de candidatos a termos (CTs) que não foram considerados conceitos especializados por especialistas da área consultados na elaboração de um glossário técnico. As autoras sugerem que se deve considerar as dúvidas apresentadas pelos alunos na compilação de um glossário como uma possível forma de auxiliar seus usuários. 


\section{COMPILANDO O CORPUS DE ESTUDO}

Conforme a matriz curricular do curso de Logística da instituição que foi contexto para este estudo, a disciplina de Inglês Instrumental acontece no $3^{\underline{0}}$ período do curso. Para esta pesquisa consideramos os dados coletados por uma das alunas dessa turma para exemplificarmos o início do desenvolvimento da proposta de DDL nas aulas de Inglês Instrumental. Vale ressaltar que, mais adiante, discorremos detalhadamente neste estudo a parte prática com os alunos nas aulas de Inglês Instrumental, cuja proposta de criação de glossário alcançou até a etapa da macroestrutura por causa de questões relacionadas à carga horária e ao uso do programa de análise lexical escolhido. Por isso, consideramos este artigo uma reflexão sobre como a metodologia DDL nessa prática explicitou questões teóricas relacionadas a TCT durante a experiência vivida com os alunos e os possíveis desdobramentos futuros para a continuidade do trabalho de DDL nas aulas de Inglês Instrumental.

Inicialmente, durante as aulas de Inglês Instrumental, foi solicitado aos alunos que desenvolvessem a tarefa de levantamento de artigos científicos da área de Logística para a criação de um corpus somente em língua inglesa, sendo que a proposta final seria compilarmos um corpus colaborativo de modo que poderíamos reunir todos os artigos encontrados, filtrando as repetições, em um único corpus compilado pela turma. Contudo não foi possível chegarmos até essa etapa, pois iniciamos esse trabalho baseado no DDL na segunda parte da disciplina, restando somente dois meses e meio para o encerramento. Assim, para esta pesquisa, escolhemos o trabalho desenvolvido por uma das alunas dessa turma. Essa aluna recebeu uma orientação individualizada durante a realização de um projeto de pesquisa, além dos encontros regulares nas aulas de Inglês Instrumental. Esse corpus foi criado a partir de 56 artigos científicos em inglês encontrados em sites de busca como Google Acadêmico e Scielo, conforme figura a seguir: 
Figura 7 - Composição de corpus - recorte

\begin{tabular}{|c|c|c|c|c|c|}
\hline & Nome & Tamanho & Tamanho Empac... & Tipo & Tempo de Modificação \\
\hline \multicolumn{6}{|c|}{." } \\
\hline & VLI has plan to invest $R \$ 9$ billion and ... & $6.1 \mathrm{~KB}$ & $2.8 \mathrm{~KB}$ & Documento de Texto & 2015-08-12 06:07:44 \\
\hline & TNT Express warns of difficult market ... & $1.0 \mathrm{~KB}$ & $575 \mathrm{~B}$ & Documento de Texto & $2015-08-12 \quad 06: 07: 42$ \\
\hline & The trucks, the soul of logistics, deserv... & $3.9 \mathrm{~KB}$ & $1.8 \mathrm{~KB}$ & Documento de Texto & 2015-08-12 06:07:40 \\
\hline & The International Journal of Logistics ... & $47.6 \mathrm{~KB}$ & $16.0 \mathrm{~KB}$ & Documento de Texto & 2015-08-12 06:07:40 \\
\hline 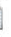 & The Instruments of Urban Logistics and... & $21.8 \mathrm{~KB}$ & $8.6 \mathrm{~KB}$ & Documento de Texto & $2015-08-12 \quad 06: 07: 38$ \\
\hline & SUPPLY CHAIN PROCESS INTEGRATIO... & $76.7 \mathrm{~KB}$ & $25.1 \mathrm{~KB}$ & Documento de Texto & 2015-08-12 06:07:36 \\
\hline 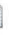 & Status of Third Party Logistics - A Com... & $20.1 \mathrm{~KB}$ & $7.0 \mathrm{~KB}$ & Documento de Texto & $2015-08-12 \quad 06: 07: 34$ \\
\hline 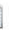 & Routing Optimization of Third Party Lo... & $31.5 \mathrm{~KB}$ & $10.6 \mathrm{~KB}$ & Documento de Texto & $2015-08-12$ 06:07:32 \\
\hline tat & State invests $\$ 34$ billion in logistics.txt & $4.0 \mathrm{~KB}$ & $1.8 \mathrm{~KB}$ & Documento de Texto & 2015-08-12 06:07:32 \\
\hline & Supply Chain and Operations Manage... & $126.3 \mathrm{~KB}$ & $48.2 \mathrm{~KB}$ & Documento de Texto & 2015-08-12 06:07:36 \\
\hline & Reverse logistics can become source $0 . .$. & $2.6 \mathrm{~KB}$ & $1.3 \mathrm{~KB}$ & Documento de Texto & 2015-08-12 06:07:30 \\
\hline & Research indicates that the country nee... & $7.3 \mathrm{~KB}$ & $3.2 \mathrm{~KB}$ & Documento de Texto & $2015-08-12 \quad 06: 07: 28$ \\
\hline & Reverse logistics packaging leave the ... & $2.7 \mathrm{~KB}$ & $1.3 \mathrm{~KB}$ & Documento de Texto & 2015-08-12 06:07:30 \\
\hline to & Research into the Long-Run Relationshi... & $22.7 \mathrm{~KB}$ & $8.3 \mathrm{~KB}$ & Documento de Texto & 2015-08-12 06:07:28 \\
\hline & Refrigeration logistics operations and ... & $50.2 \mathrm{~KB}$ & $18.1 \mathrm{~KB}$ & Documento de Texto & $2015-08-12 \quad 06: 07: 26$ \\
\hline & Poor logistics new frontier lock for grai... & $4.3 \mathrm{~KB}$ & $2.0 \mathrm{~KB}$ & Documento de Texto & 2015-08-12 06:07:24 \\
\hline 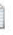 & Plan infrastructure and logistics for car... & $2.3 \mathrm{~KB}$ & $1.1 \mathrm{~KB}$ & Documento de Texto & $2015-08-12 \quad 06: 07: 22$ \\
\hline & Procurement - Performance-based Lo... & $.16 .8 \mathrm{~KB}$ & $6.3 \mathrm{~KB}$ & Documento de Texto & 2015-08-12 06:07:24 \\
\hline & Output by the North acirrará logistics c... & $1.9 \mathrm{~KB}$ & $961 \mathrm{~B}$ & Documento de Texto & 2015-08-12 06:07:22 \\
\hline tat & Opening panel at the National Logistic... & $6.1 \mathrm{~KB}$ & $2.8 \mathrm{~KB}$ & Documento de Texto & 2015-08-12 06:07:20 \\
\hline & Northern Parana is in the eye of the st... & $2.3 \mathrm{~KB}$ & $1.1 \mathrm{~KB}$ & Documento de Texto & $2015-08-12$ 06:07:18 \\
\hline 1 & More intelligent, cost effective and envi... & $3.2 \mathrm{~KB}$ & $1.5 \mathrm{~KB}$ & Documento de Texto & 2015-08-12 06:07:16 \\
\hline 10 & METODOLOGÍA Y LOGÍSTICA DE CAMP... & $.57 .5 \mathrm{~KB}$ & $21.7 \mathrm{~KB}$ & Documento de Texto & $2015-08-12$ 06:07:16 \\
\hline & Myriad Bottlenecks.txt & $16.0 \mathrm{~KB}$ & $6.6 \mathrm{~KB}$ & Documento de Texto & $2015-08-12$ 06:07:18 \\
\hline 1 & Logistics training.txt & $13.8 \mathrm{~KB}$ & $5.5 \mathrm{~KB}$ & Documento de Texto & 2015-08-12 06:07:14 \\
\hline 1 & Logistics Problems in the US.txt & $2.2 \mathrm{~KB}$ & $1.1 \mathrm{~KB}$ & Documento de Texto & $2015-08-12$ 06:07:14 \\
\hline & Logistics Make the World Go Round, a... & $11.2 \mathrm{~KB}$ & $4.9 \mathrm{~KB}$ & Documento de Texto & 2015-08-12 06:07:12 \\
\hline & Logistics costs in Brazil should be redu... & $2.2 \mathrm{~KB}$ & $1.1 \mathrm{~KB}$ & Documento de Texto & 2015-08-12 06:07:10 \\
\hline & Logistical monster.txt & $2.6 \mathrm{~KB}$ & $1.3 \mathrm{~KB}$ & Documento de Texto & $2015-08-12$ 06:07:06 \\
\hline & Logistics is 17_ of the price of soybean... & $1.2 \mathrm{~KB}$ & $672 \mathrm{~B}$ & Documento de Texto & 2015-08-12 06:07:12 \\
\hline & Logistics condominium market remains... & $1.5 \mathrm{~KB}$ & $789 \mathrm{~B}$ & Documento de Texto & $2015-08-12 \quad 06: 07: 08$ \\
\hline & Loaistics consumes 11.2 of revenue an... & $3.4 \mathrm{~KB}$ & $1.5 \mathrm{~KB}$ & Documento de Texto & 2015-08-12 06:07:08 \\
\hline
\end{tabular}

Segundo Fromm (2014), no projeto de construção de um corpus colaborativo, deve-se estabelecer um parâmetro de palavras para cada subárea em cada idioma para que o corpus se torne balanceado. O autor faz referência a Berber-Sardinha (2004) para explicar que o corpus deve ser composto de textos autênticos, selecionados de forma criteriosa e sendo representativos na análise. Durante esta pesquisa, os alunos dessa turma de Inglês Instrumental fizeram o levantamento do corpus somente em língua inglesa e, nesse primeiro momento, não foi estabelecido um parâmetro de quantidade de palavras. Mais adiante, explicamos que, para a continuidade desta pesquisa, compilaremos um corpus de 500 mil palavras em ambos os idiomas: inglês e português, com a finalidade de criarmos um vocabulário específico da área de acordo com a microestrutura do Vocabulário Técnico On-line - Votec (FROMM, 2007). 


\section{ORGANIZANDO A MACROESTRUTURA}

Para o processamento de linguagem do corpus compilado tivemos duas opções de programas para análise do léxico: Antconc (ANTHONY, 2011) e Wordsmith Tools (SCOTT, 2012). Ambos apresentam ferramentas para se criar a listagem de palavras, palavras-chave e concordanciador. Para esta pesquisa, escolhemos usar o Antconc com os alunos em sala de aula por ser um software gratuito. Porém, em razão de alguns problemas do AntConc, como a impossibilidade de usar um corpus de referência na análise da chavicidade das palavras, tivemos que utilizar o Wordsmith Tools (versão paga) para gerarmos uma lista de palavras-chave.

Figura 8 - Tela inicial do Antconc.

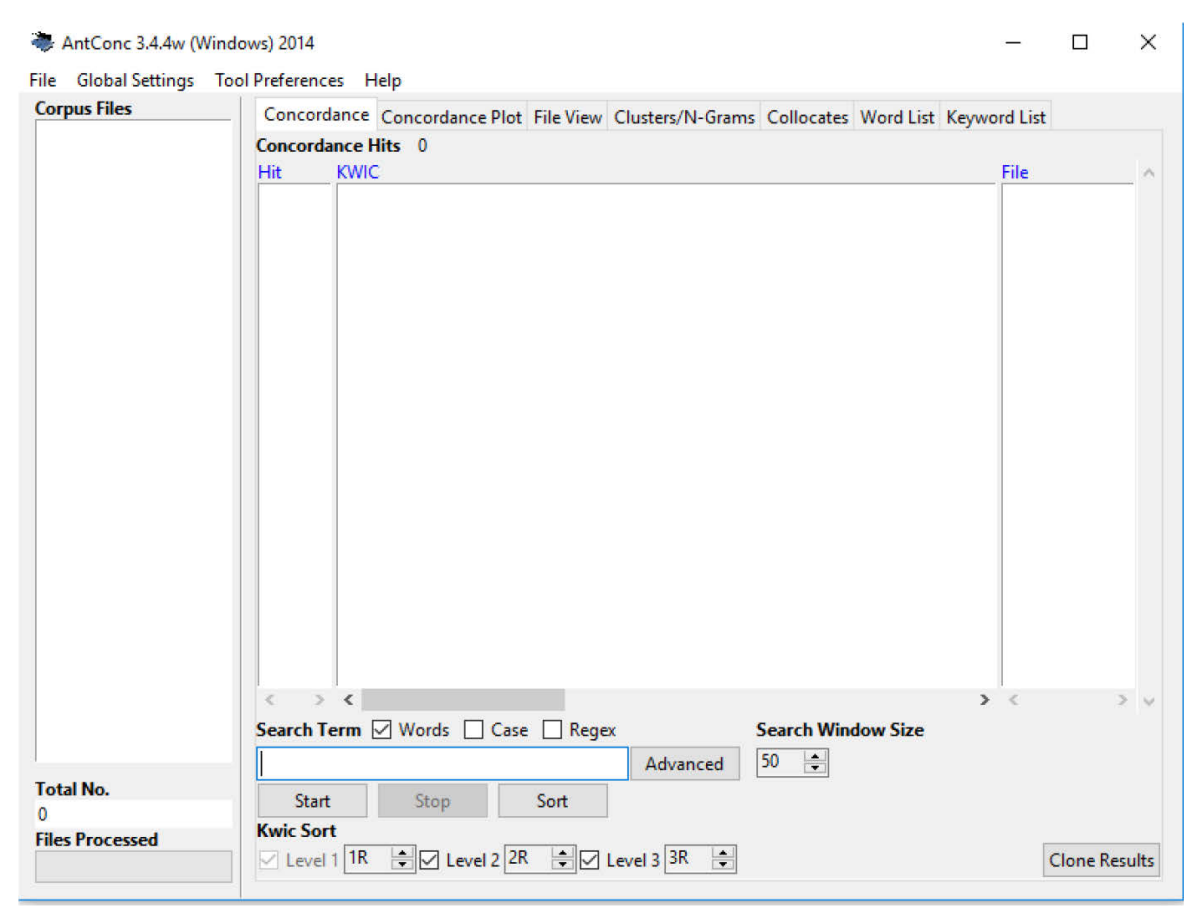

Além da gratuidade do Antconc, foi muito simples usar esse programa no laboratório de informática do campus, cujas normas demandam uma burocracia para a instalação de softwares pelos funcionários responsáveis. Pelo fato do Antconc ser um arquivo executável não havia a necessidade de instalar o programa nos computadores. Porém, as listas de palavras criadas por esse programa não ficam salvas. Logo, os 
alunos tinham de acessar o site do Antconc e fazer todo o procedimento todas as vezes que o utilizamos. Vimos como uma desvantagem termos de fazer a listagem de palavras sempre que precisávamos fazer a análise lexical, porque demandava tempo de trabalho.

A seguir apresentamos a listagem de palavras criada pela aluna a partir do corpus compilado por ela. Podemos notar que a listagem de palavras apresenta os seguintes dados numéricos: número total de palavras de textos, ou tokens, quantas palavras diferentes há no corpus (types), frequência numérica de cada palavra e a ordem de cada palavra de acordo com a frequência. Fromm (2014) destaca que a listagem de palavras é uma ferramenta fundamental porque é a base para que as outras funcionem.

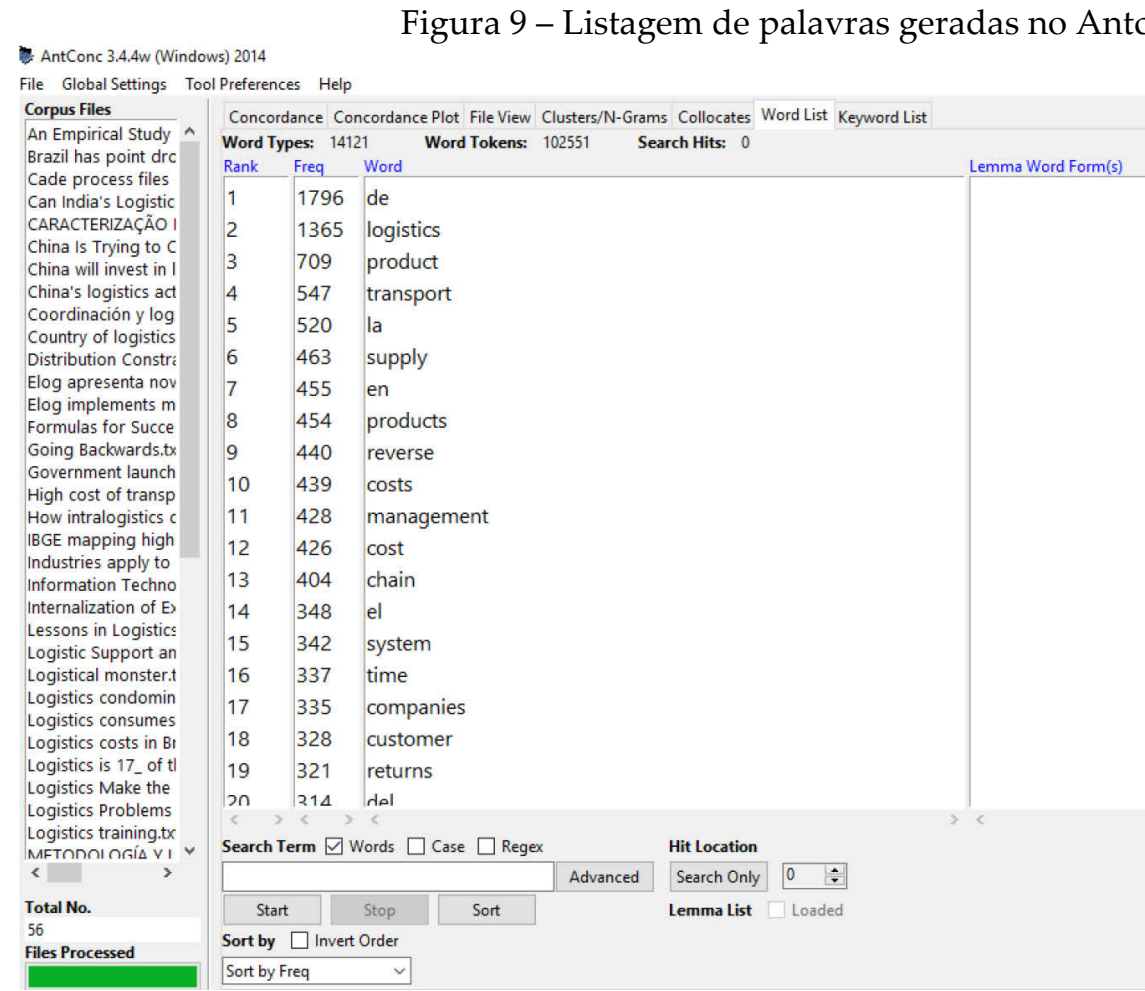

Essa lista de palavras, Figura 9, foi elaborada pelo corpus compilado por meio de 56 artigos científicos da área de Logística, usando uma stoplist de palavras 
gramaticais da língua inglesa. O uso da stoptlist permitiu que palavras gramaticais, como artigos, numerais e pronomes demonstrativos, fossem excluídas na lista de palavras gerada pelo programa. O Antconc possibilita a inserção de uma stoptlist na aba Tool Preference.

Observando a listagem de palavras geradas no Antconc (Figura 9) identificamos na parte inferior da primeira aba à esquerda que o corpus de Logística em inglês é composto de 56 textos. Já o número total de palavras (Word Tokens) do corpus é 102.551 e está na segunda linha, centralizado na parte superior da janela.

O próximo passo da análise foi a criação da lista de palavras-chave que nos auxilia a descobrir quais são os termos que fazem parte da área da Logística. É por meio da ferramenta de palavras-chave que podemos descobrir os possíveis termos que serão relacionados na criação do vocabulário específico da área.

Usando o mesmo corpus em questão decidimos usar o Wordsmith, porque a versão do Antconc utilizada com os alunos em sala de aula apresentava problemas para carregar um corpus de referência, necessário para a criação de uma listagem de palavras-chave (keyword list). Fromm (2014, p. 270) explica que os corpora de referência são corpora gerais de língua, no mínimo cinco vezes maior que o de estudo e que não contenha esse corpus de estudo. Para esta pesquisa, utilizamos o Coca (DAVIES, 2013) por ser o corpus de referência em inglês e consistir em cem mil palavras únicas em suas listas.

O programa Wordsmith Tools oferece uma análise estatística ao criar a lista de palavras e nos indica quais palavras tem chavicidade positiva ou negativa no corpus de estudo. Segundo Fromm (2014) a palavra-chave positiva representa a palavra que aparece mais do que deveria em relação ao corpus de referência, já as palavras-chave negativas são menos frequentes do que deveriam. 
Figura 10 - Listagem de palavras-chave geradas no Wordsmith.

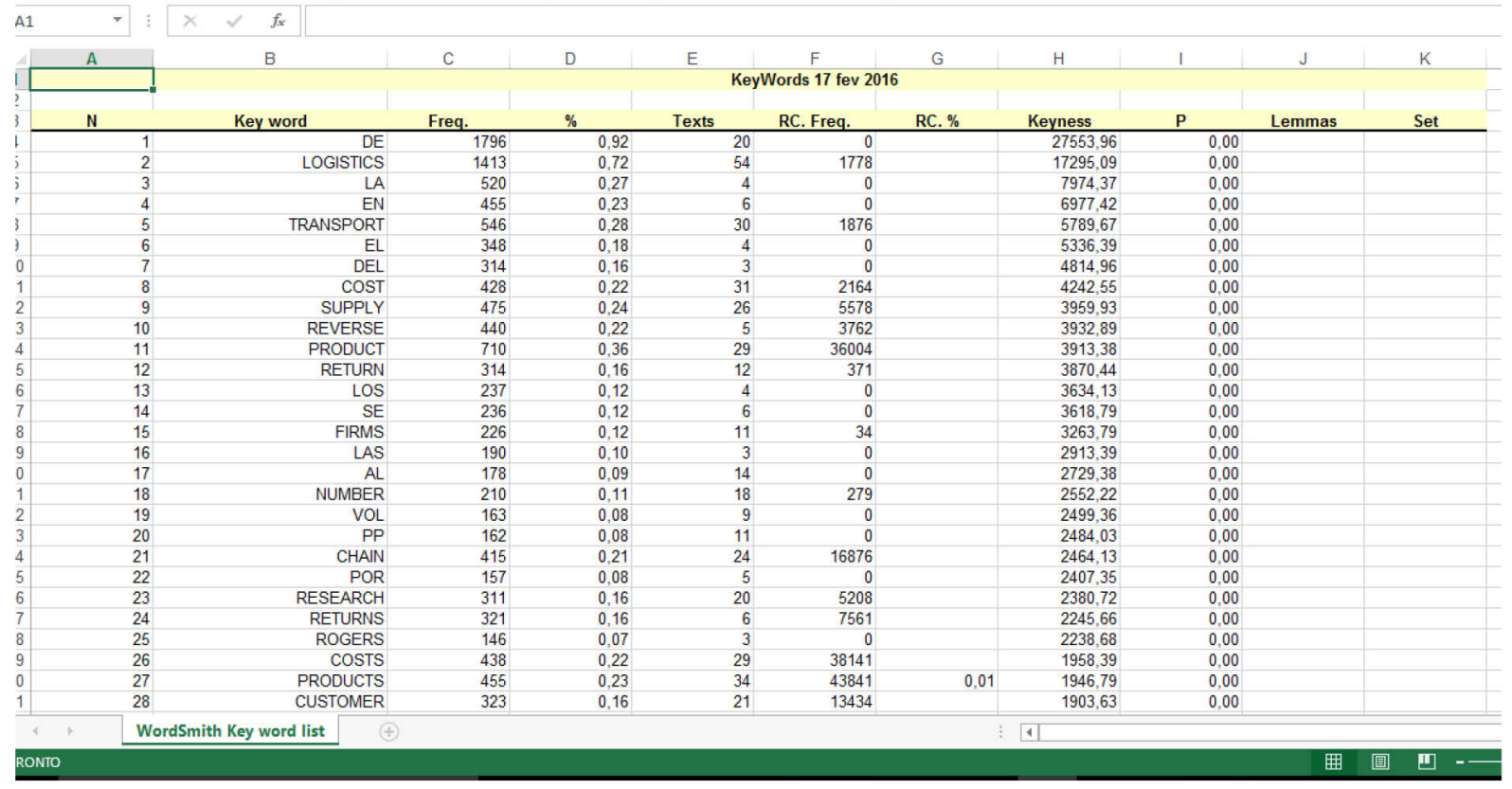

Como nesse primeiro momento trabalhamos somente o corpus em língua inglesa, não nos preocupamos em encontrar palavras-chave que fossem equivalentes no inglês e no português.

Observando a listagem de palavras-chave geradas no Wordsmith (Figura 10), notamos as palavras-chave relacionadas à área de Logística que estão no topo da lista: LOGISTICS, TRANSPORT, COST, SUPPLY E REVERSE. Essas palavras têm certa semelhança de posição com a listagem de palavras-chave criada no AntConc (Figura 9): LOGISTICS, PRODUCT, TRANSPORT, SUPPLY, REVERSE, COSTS. Nessa comparação, somente a palavra product não foi listada com a mesma frequência pelos programas.

É importante explicarmos que os alunos usaram somente o Antconc e desenvolveram as atividades em sala de aula até essa etapa de identificação de cinco termos. A geração da lista de palavras-chave no Wordsmith foi feita em outro computador que tinha esse software instalado.

Após essa etapa, a tarefa que os alunos deveriam desenvolver envolvia escolher um termo na lista de palavras-chave e analisar as suas linhas de concordância. Para 
analisar as linhas de concordância é necessário clicar na aba concordance que fica no topo superior.

Figura 11 - Linhas de concordância geradas no Antconc para o termo logistics.

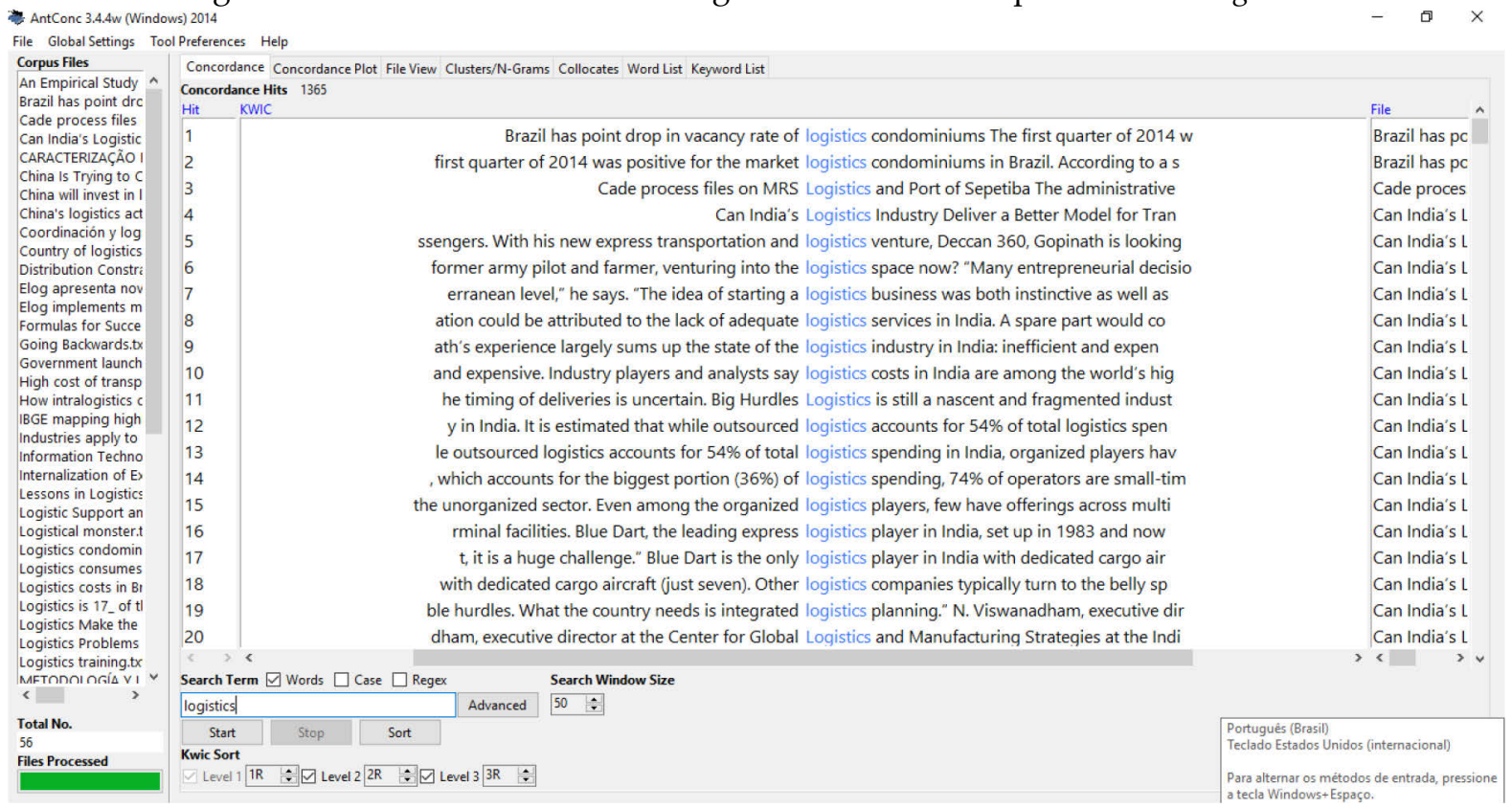

Nas linhas de concordância, o termo escolhido a ser trabalhado pelo aluno deve ser identificado por estar centralizado, em cor diferente de fonte, exibindo a linha da qual ele foi extraído. Durante as aulas e o trabalho individualizado com a aluna, cujo material ilustrou este estudo, alcançamos até essa etapa da macroestrutura. Então, a continuidade do trabalho com os alunos deve continuar desse ponto para que possamos transferir os exemplos das linhas de concordância para o banco de dados e, posteriormente, elaborar a definição do termo.

\section{Resultados do estudo}

Alguns resultados obtidos ao longo deste estudo referem-se à estrutura atual do corpus e à macroestrutura desenvolvida pela aluna-participante da pesquisa. 
Sobre a estrutura atual, o corpus é composto por 56 textos em língua inglesa, artigos científicos da área da Logística, e o número total de palavras (Word Tokens) do corpus é 102.551.

No que diz respeito à macroestrutura, que consistiu na escolha dos termos que comporão o vocabulário da área, por meio do uso do programa de análise lexical Wordsmith, foi criada a lista de palavras-chave (Figura 10). Ao observar a listagem de palavras-chave gerada pelo Wordsmith Tools e a lista de palavras gerada pelo Antconc, notamos que elas se aproximam.

Utilizando somente o Antconc, foram destacadas pela aluna as seguintes cinco palavras: LOGISTICS, PRODUCT, TRANSPORT, SUPPLY, REVERSE e COSTS. Apesar de não ter sido utilizado um corpus de referência, ao comparar esses dados com a listagem de palavras-chave geradas pelo Wordsmith, podemos ver que a relação de termos localizados nas posições mais frequentes ficou bem próxima.

Figura 11 - Comparação entre as listagens de palavras-chave.
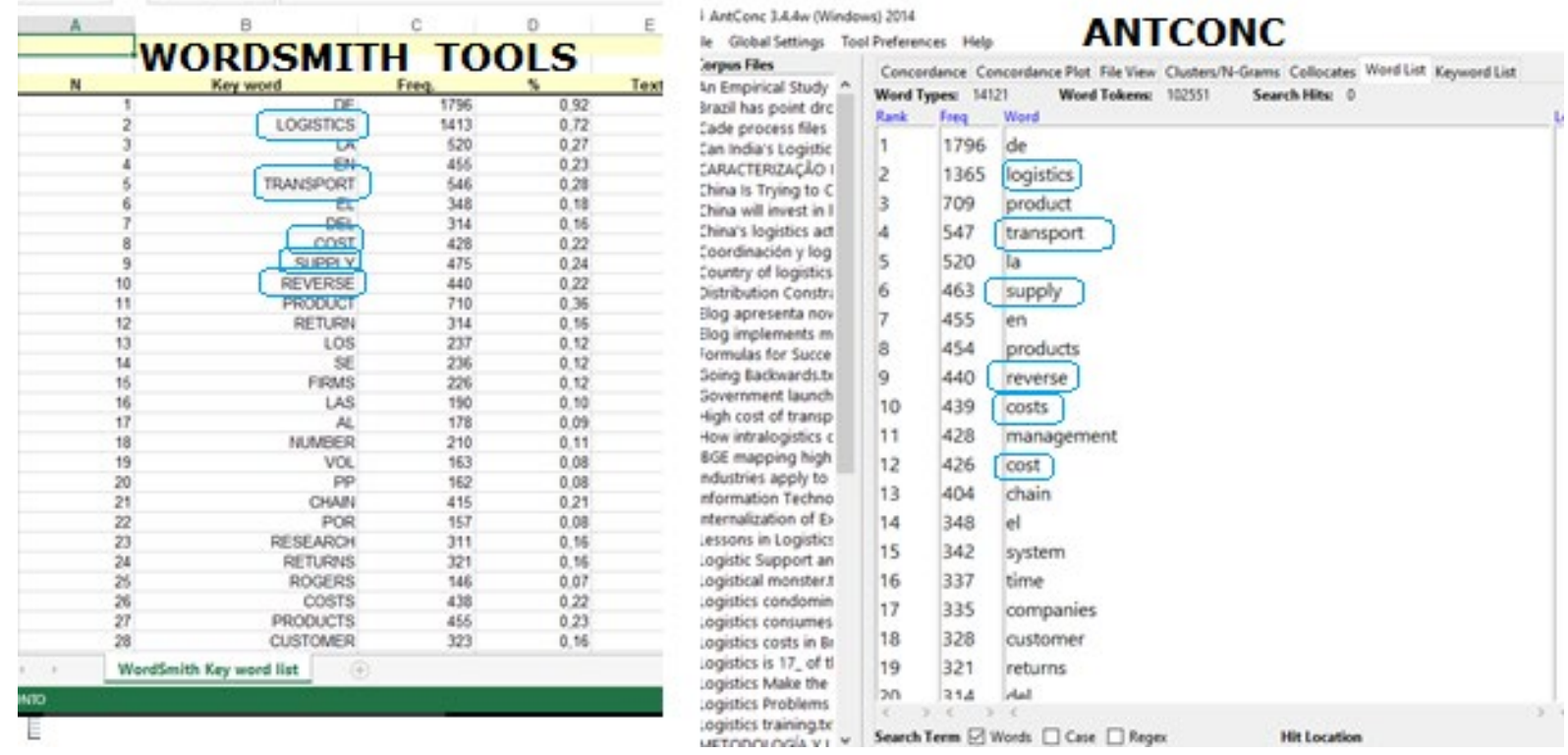

Nessa relação comparativa dos programas de análise lexical percebemos a proximidade dos resultados entre as listas de palavras-chave e a listagem de palavras. 
Assim, será possível continuar a usar o Antconc na sala de aula apesar de suas restrições.

Ao longo deste artigo nos propusemos apresentar uma reflexão sobre a possibilidade de uso da metodologia da Linguística de Corpus no ensino e na aprendizagem de língua inglesa na perspectiva do DDL. Dessa forma, informamos as possibilidades de uso da Linguística de Corpus em sala de aula, descrevemos a proposta de pesquisa que foi desenvolvida e suas limitações, além de observar na perspectiva prática as questões teórico-metodológicas que envolveram o estudo: Datadriven Learning (DDL) (JOHNS, 1991), Teoria Comunicativa da Terminologia (TCT) (ALMEIDA, 2006) e Linguística de Corpus (BERBER-SARDINHA, 2004).

A seguir apresentamos os possíveis desdobramentos para a continuidade desta pesquisa e os futuros estudos sobre a temática.

\section{ALGUNS DESDOBRAMENTOS FUTUROS}

Conforme mencionado anteriormente, acreditamos na possibilidade de continuidade desta pesquisa nesse mesmo contexto, mas com o objetivo de investigar como o conhecimento em língua inglesa dos alunos pode ser construído por meio de atividades DDL. Penso que os resultados apresentados nesse estudo podem ser considerados como um indício de que é possível trabalhar com alunos de Inglês Instrumental de um curso de Logística, ainda que não sejam da área de Linguística, na criação do próprio material didático para as aulas de inglês por meio da Linguística de Corpus. Durante o desenvolvimento das atividades, alguns alunos comentavam suas impressões sobre o trabalho e compartilhavam suas considerações sobre o que tinham aprendido. Assim, seria importante desenvolver uma pesquisa com objetivos direcionados a entender as implicações do uso da metodologia da Linguística de Corpus na aprendizagem de inglês. Neste estudo, percebemos que os alunos envolvidos na pesquisa apresentaram ganhos de proficiência nessa língua ao 
relatarem durante a conversa com a professora e colegas que durante a realização da tarefa de compilação do corpus e uso do AntConc, foram aprendendo a conhecer as fontes de pesquisa de artigos científicos da área da Logística, a relacionar o seu próprio conhecimento prévio na interpretação dos textos em inglês e a utilizar ferramentas de tradução on-line, como dicionários e o Google Tradutor. Vale destacar que para a utilização do programa Antconc além das explicações fornecidas pela professora, foi observado que os alunos buscavam tutoriais no próprio site do Antconc, bem como em vídeos disponíveis em inglês no Youtube. Como professora percebo que, além de ganhos na proficiência em língua inglesa, os alunos também se desenvolveram em relação ao letramento digital no uso das ferramentas digitais trabalhadas durante as aulas de Inglês Instrumental.

Outra etapa de continuidade desta pesquisa seria continuar o estudo sobre a criação de um vocabulário da área de Logística, bilíngue: português/inglês, com os alunos do curso de Tecnologia em Logística. O próximo passo poderia ser a compilação de um corpus coletivo, usando o material de cada um dos alunos, a atualização da macroestrutura por meio da criação das listas de palavras, das palavraschave e das linhas de concordância conforme exemplificado neste artigo. Depois dessa etapa, seria necessário organizar a microestrutura seguindo as definições de microestrutura estipuladas pelo Votec - Vocabulário Técnico On-line (FROMM, 2009).

Segundo Fromm (2009), o Votec é distinto de outras ferramentas eletrônicas disponíveis no mercado na construção de um corpus de estudo, porque se baseia na elaboração de sua macro e microestrutura apenas em corpora técnicos especialmente construídos para esse fim que servem de base para a ferramenta na construção de uma árvore de campo da área de Linguística e Linguística Aplicada.

A seguir um exemplo dessa microestrutura por meio da ficha terminológica informatizada do Votec: 
Figura 12 - Criação do termo Supply Chain.

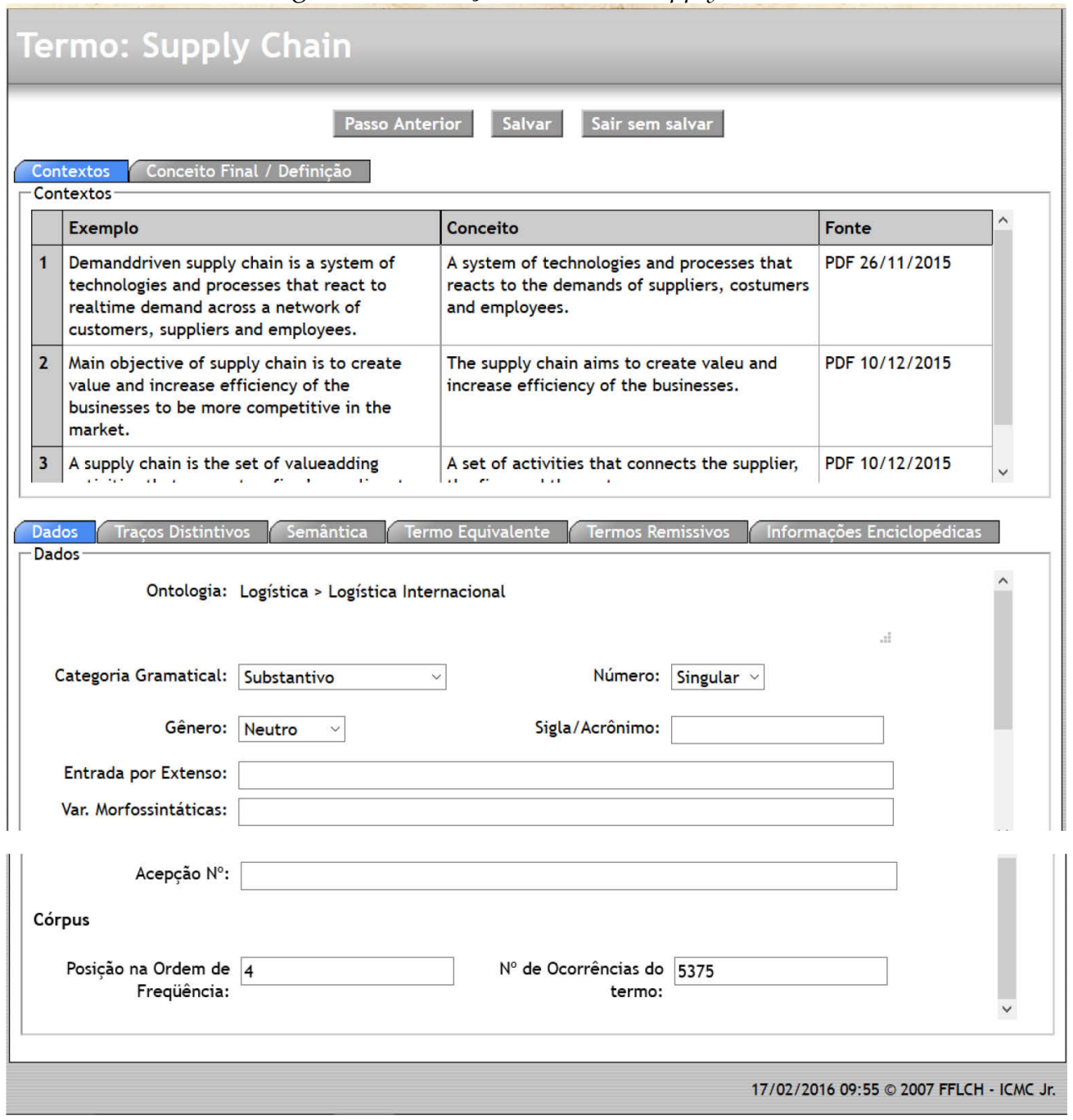

Sobre a elaboração da ficha terminológica, Fromm (2014) esclarece que os campos dessa ficha disponível no Votec pressupõem que toda informação a ser inserida deve ser baseada somente no corpus de estudo.

A microestrutura se constitui, primeiramente, do cadastro de exemplos sobre determinado termo. No link "Contextos", é necessário inserir as linhas de concordância selecionadas a partir do corpus, na sequência, ao lançar cada exemplo cadastrado, deve-se procurar criar um resumo, uma simplificação ou uma explicação de modo a gerar o conceito para o termo.

Na aba inferior, Traços Distintivos é o campo em que é feita uma análise componencial de temas criados por meio de conceitos do conhecimento prévio. 
Segundo Fromm (2014) a última tarefa é a criação do conceito final e da definição para o verbete em análise.

Certamente há outros desdobramentos que não relacionamos neste estudo, por isso, intitulamos essa seção dessa forma. Apresentamos algumas possibilidades de desdobramentos de pesquisa. A seguir, discorremos sobre as nossas considerações.

\section{Considerações}

Desenvolver esta pesquisa assumindo o papel de professora de Inglês Instrumental e pesquisadora propiciou um olhar reflexivo voltado para o meu próprio contexto de sala de aula. Penso que essa oportunidade de estudo me fez perceber que há muitas possibilidades de uso da metodologia da Linguística de Corpus no ensino e na aprendizagem de língua inglesa na perspectiva do DDL. Vivi com meus alunos a experiência de ensinar e aprender a língua inglesa por meio da leitura de textos autênticos da área de formação profissional. Foi possível notar que embora alguns alunos tivessem um nível básico de proficiência em inglês, eles conseguiram desempenhar as tarefas completamente, desde a identificação de textos específicos da área da Logística em inglês, por meio da leitura e interpretação dos resumos (abstracts) dos textos pesquisados às tarefas operativas de compilação do corpus.

Uma das vantagens de se considerar a perspectiva do DDL nas aulas de inglês é a oportunidade de criar material didático adequado às necessidades dos alunos. Acredito que envolver o aluno nesse processo de elaboração de material pode trazer benefícios para o próprio estudante que se torna mais independente para aprender a língua inglesa e passa a conhecer, ainda que de modo introdutório, sobre o funcionamento da linguagem. Portanto, o caráter de trabalho colaborativo com os alunos na produção de material didático é possível por meio da metodologia do DDL, que permite que os próprios alunos em aula, juntamente com o professor, organizem uma coleção de textos em inglês para serem estudos durante as aulas de Inglês 
Instrumental, as quais se tornam mais próximas às necessidades dos alunos de aprender a língua estrangeira.

\section{Referências}

DE BARCELLOS ALMEIDA, G. M. A Teoria Comunicativa da Terminologia e a sua prática. Alfa: revista de Linguística. São Paulo, v. 50, n. 2. 2006.

ANTHONY, L. AntConc (Version 3.4. 3) [Computer Software]. Tokyo, Japan: Waseda University. 2014.

ANTHONY, L. AntConc 3.4.3. Tokyo: Waseda University, 2014. Disponível em: http://www.laurenceanthony.net/software/antconc/. Acesso em: 21 fev. 2015.

DORNELLES, M. S. Bases teórico-metodológicas para elaboração de um glossário bilíngue (Português-Inglês) de Treinamento de Força: subsídios para o tradutor. Porto Alegre, 2015. 365 p. Dissertação (Mestrado) - Programa de Pós-graduação em Letras - PPG-UFGRS, Universidade Federal do Rio Grande do Sul, 2015. DOI https://doi.org/10.29289/259453942018v28s1059

FADANELLI, S. B.; FINATTO, M. J. B. A arquitetura de um glossário terminológico Inglês-Português na área de Eletrotécnica. Linguamática. v. 7, n. 1, p. 67-71, 2015.

FROMM, G. Elaboração de um verbete bilíngue na área de aquisição da linguagem. In: GONÇALVES, A. V.; SILVA, W. R.; GÓIS, M. L. de S (org.). Viabilizar a Linguística Aplicada: abordagens teóricas e metodológicas. Campinas, SP: Pontes, 2014.

FROMM, G. VoTec: página de terminologia para tradutores. Estudos Linguísticos. São Paulo, v. 38, n. 1, p. 183-199, 2009.

JOHNS, T. F. Should you be persuaded: two samples of data-driven learning materials. In: JOHNS, T. F.; KING, P. (org.). Classroom Concordancing. Birmingham: ELR Journal, v. 4, p. 1-16, 1991.

KRIEGER, M. da G.; FINATTO, M. J. B. Introdução à Terminologia: teoria e prática. São Paulo: Contexto, 2004.

MA, K. C. Small-corpora concordancing in ESL teaching and learning. Hong Kong Papers in Linguistics and Language Teaching. v. 16, p. 11-30, 1993. 
PEIXOTO, L. M.; BRITO, L. F. A. Procedimentos para compilação de um corpus composto por legendas e construção de uma ferramenta de corpus on-line: o Corpus of English Language Videos. Domínios da linguagem. Uberlândia, v. 9, n. 3, p. 275299, 2015. DOI https://doi.org/10.14393/dl19-v9n3a2015-15

SARDINHA, T. B. Linguística de corpus. Barueri, SP: Manole, 2004.

SCOTT, M. WordSmith tools version 5. Liverpool: Lexical Analysis Software. Oxford: Oxford University Press, v.122, 2008

SMITH, S. Corpora in the classroom: data-driven learning for Freshman English. Disponível em: http://www3.nccu.edu.tw/ smithsgj/Corpora $\% 20 \mathrm{in} \% 20$ the $\% 20$ classroom.pdf. Acesso em: 12 fev. 2015.

SMITH, S. et al. Corpora for SLA: using Sketch Engineto learn Chinese and English. In: Proceedings 2007 Conference and Workshop on TEFL and Applied Linguistics. Taoyuan, p. 430-436, 2007.

VIANA, V.; TAGNIN, S. E. O. (org.). Corpora no ensino de línguas estrangeiras. São Paulo, SP: HUB Editorial, 2011. 